\title{
Antimicrobial Efficacy of Triphala and Propolis-modified Glass Ionomer Cement: An In Vitro Study
}

Jessy Paulraj ${ }^{1}$, Priya Nagar ${ }^{2}$

\begin{abstract}
Background: The antimicrobial activity of restorative materials has a major role in preventing recurrent caries.

Aim: To assess the antimicrobial activity of triphala and propolis-modified glass ionomer cement (GIC) against Streptococcus mutans and Lactobacillus.

Materials and methods: The samples were prepared using cylindrical molds ( $6 \mathrm{~mm}$ in diameter and $2 \mathrm{~mm}$ in thickness). A total of 30 samples were prepared containing 10 samples in each group. Group I, 10 samples of glass ionomer with aqueous extract of triphala were prepared; group II, 10 samples of glass ionomer with $50 \%$ of ethanolic extract of propolis (EEP); and group III as control consisting of 10 samples of glass ionomer. The samples were placed in to agar plates containing inoculum of S. mutans and Lactobacillus and incubated at $37^{\circ} \mathrm{C}$ for 48 hours and using a digital caliper, zones of inhibition formed around specimens were measured.

Results: Data obtained were analyzed using nonparametric Kruskal-Wallis test followed by pairwise comparison was done using Dunn-Bonferroni test. Group I and group II showed highest antimicrobial efficacy against S. mutans and Lactobacillus with no statistical significant difference, i.e., ( $p$ value $>0.05$ ) but in both groups I and II, there was a statistical significant difference when comparing with group III i.e., $(p<0.05)$.

Conclusion:Thus, triphala and propolis-modified GIC provided higher antibacterial effect with increased level of inhibition against the $S$. mutans and Lactobacillus; hence, it can be used as a choice of restorative material to treat dental caries. Further studies are required to determine the physical and mechanical characteristics of the material.
\end{abstract}

Keywords: Antibacterial effect, Glass ionomer cement, Lactobacillus, Propolis, S. mutans, Triphala.

International Journal of Clinical Pediatric Dentistry (2020): 10.5005/jp-journals-10005-1806

\section{INTRODUCTION}

The cariogenic bacteria responsible for dental caries are fixed in the dental plaque which are predominantly Streptococcus mutans and Lactobacillus acidophilus. ${ }^{1,2}$ Microbial infection is the main cause for the inflammation of the dental pulp and periodontium. Previous literature indicates the existence of residual traces of infection in the site affects the success of restoration resulting in secondary caries. ${ }^{3}$ Secondary caries process is difficult to diagnose and cannot be permanently treated by operative management.

Glass ionomer cements (GICs) are widely used in permanent restorations as a cavity liner, fissure sealants, and adhesives. It releases fluoride ions that act as anticariogenic agent and helps in prevention of oral problems such as enamel demineralization, remineralization, and also interferes with the bacterial growth and metabolism, ${ }^{4}$ but it can reduce the microbial count to a certain extent. It is effective against some pathogens but not all oral pathogens causing cariogenic and periodontal problems. With the spectrum of bacteria inhibited by fluoride being inadequate, therefore, a restorative material that can create persistent antimicrobial environment around the restoration would be considerable to provide clinical benefit in reducing dental caries, plaque accumulation, and periodontal problems. Due to increased occurrence of recurrent caries after restorative treatment, much attention is required in the use of direct filling materials. Different modifications of GICs have been suggested in previous literature to enhance its antimicrobial properties. Triphala is an ayurvedic herbal formulation contains three medicinal plants T. chebula, T. belerica, and Phyllanthus embelica, which has been proven to have numerous benefits. This magical preparation has action on all the three
${ }^{1}$ Department of Pedodontics and Preventive Dentistry, Saveetha Dental College, Saveetha Institute of Medical and Technical Sciences, Saveetha University, Chennai, Tamil Nadu, India

${ }^{2}$ Department of Pedodontics and Preventive Dentistry, Krishnadevaraya College of Dental Sciences and Hospital, Bengaluru, Karnataka, India

Corresponding Author: Jessy Paulraj, Department of Pedodontics and Preventive Dentistry, Saveetha Dental College, Saveetha Institute of Medical and Technical Sciences, Saveetha University, Chennai, Tamil Nadu, India, Phone: +91 8861646189, e-mail: drjessy2019@gmail.com

How to cite this article: Paulraj J, Nagar P. Antimicrobial Efficacy of Triphala and Propolis-modified Glass lonomer Cement: An In Vitro Study. Int J Clin Pediatr Dent 2020;13(5):457-462.

Source of support: Nil

Conflict of interest: None

components considered in Ayurveda-Vata, Pitta, and Kapha. Such a large range of action of triphala is supposed to be because of the 47 tannins and 35 phytochemicals. ${ }^{5,6}$ Surprisingly, its mechanism of action has been less studied, and it has been expected to have an antimicrobial effect as said by previous literature. The study done by Srinagesh et al. suggested the anti-oral streptococci efficacy of triphala. ${ }^{7}$

Propolis, known for its antioxidant properties, was widely consumed since ancient times as a folk medicine. ${ }^{8}$ In addition to antioxidant activity, it also contains numerous other benefits ${ }^{9,10}$ that have been used till date in current medicine with a trend of "back to nature". The study reported by Yang et al. and Uzel et al. stated that there was a antimicrobial activity of propolis against S. mutans. ${ }^{11,12}$ 
Another study done by de Carvalho Duailibe et al. proved that extract of propolis has an excellent antimicrobial activity against S. mutans which can be an alternate measure to prevent dental caries. ${ }^{13}$ Keeping this in mind, the present study was planned to evaluate the antimicrobial efficacy of GIC-modified triphala and propolis against $S$. mutans and Lactobacillus.

\section{Materials and Methods}

\section{Preparation of Ethanolic Extract of Propolis (EEP)}

Propolis was supplied by Hitech Natural Lab, Delhi. The samples were grinded and preserved in container in 10-g portions. Using the magnetic mixer, the grinded samples were dissolved in $20 \mathrm{~mL}$ of ethanol. The rough particles were filtered, and the final extract of propolis was obtained.

\section{Preparation of Aqueous Extract of Triphala (AET)}

Triphala (IMPCOPS Ltd., Chennai, India) powder was transferred to solution by dissolving with $10 \%$ dimethyl sulfoxide (DMSO) (S.D. Fine Chem Pvt. Ltd., India). The previous literature states that pure properties of the herb can be attained even after mixing it with DMSO, as it is a highly polar, aprotic solvent ${ }^{14,15}$ and hence it was used.

\section{Bacterial Strain and Inoculum Preparation}

Streptococcus mutans (ATCC 25175) and Lactobacillus acidophilus (ATCC 4356) were obtained from Bioline laboratories, Delhi. The agar well diffusion method was done to test the antimicrobial efficacy of ethanolic extract of propolis (EEP) and aqueous extracts of triphala (AET) against these bacterial strains.

A sterile complete loop of the pure culture of $S$. mutans was taken, and the facultative strains of $S$. mutans were fully grown on brain heart infusion agar. The microorganisms were subcultured in appropriate culture media and under gaseous conditions to improve purity, and it was inoculated individually in tubes containing $5 \mathrm{~mL}$ of sterile saline. The suspension was then adjusted to 0.5 Mcfarland scale $=1.5 \times 10^{8}$ colony-forming unit (CFU).

\section{Determination of Minimal Inhibitory Concentration (MIC)}

The MIC of EEP and AET against the bacterial strains. i.e., S. mutans and Lactobacillus was determined using the agar dilution method. The solution was serially diluted till the least concentration, the level at which inhibition was achieved toward the growth of S. mutans and L. acidophillus and was recorded as the MIC of the extract.

\section{Specimen Preparation}

The type IX GIC (GC corporation, Tokyo) was used in the present study.

- Group I: Triphala extract $\left(\mathrm{L}^{\mathrm{AET}}\right)$ mixed with powder $\left(\mathrm{P}^{\mathrm{GIC}}\right)$ and liquid $\left(\mathrm{L}^{\mathrm{GIC}}\right)$ of $\mathrm{GIC}\left(\mathrm{P}^{\mathrm{GIC}}: \mathrm{L}^{\mathrm{GIC}}: \mathrm{L}^{\mathrm{AET}}\right.$ ratio = 1:0.5:0.5)

- Group II: 50\% EEP ( $\left.\mathrm{L}^{\mathrm{EEP}}\right)$ added with powder $\left(\mathrm{P}^{\mathrm{GIC}}\right)$ and liquid $\left(\mathrm{L}^{\mathrm{GlC}}\right)$ of $\mathrm{GIC}\left(\mathrm{P}^{\mathrm{GIC}}: \mathrm{L}^{\mathrm{GIC}}: \mathrm{L}^{\mathrm{EEP}}\right.$ ratio = 1:0.5:0.5)

- Group III: Conventional GIC (PGIC:LIC ratio = 1:1) (Fig. 1).

After mixing the powder and liquid of conventional GIC, the liquid extract of propolis and triphala was incorporated. The final obtained cement was placed into cylindrical molds measuring diameter of $6 \mathrm{~mm}$ and $2 \mathrm{~mm}$ in thickness (Fig. 2), and the prepared specimens were carried to the cylindrical wells in less than 1 minute using the sterile cement carrier, and the upper surface of the cement layer was pressed to the equal level using sterile glass slide. After setting of the cement, the disk-shaped specimens were removed from the mold. The precise specimen was measured using calipers and recorded. Overall total of 30 specimens were obtained (Fig. 3).

\section{Antimicrobial Assay Using Agar Disk Diffusion Test}

Standard strains S. mutans and Lactobacillus were used to test the antimicrobial efficacy of two different restorative materials. Brain heart infusion broth is used for culture. Ten agar plates were used. Using a sterile swab, the surface of each agar plate was swabbed 3 times to ensure even distribution of the inoculum. After drying the agar plates, three wells of $6 \times 2 \mathrm{~mm}$ diameter were made in each agar pate using sterile agar punchers, and set disk-shaped specimens were inserted into the wells after which the plates were set for incubation aerobically at $37^{\circ} \mathrm{C}$ for 48 hours. The zones of inhibition were measured based on the concept of Takahashi et al. ${ }^{16}$ Digital caliper was used for measuring the inhibition zones.

\section{Statistical Analysis}

The obtained values were entered in MS excel spreadsheet, and the data were imported to SPSS (Statistical Package for Social Sciences) Version 20.1 (Chicago, USA Inc.). The descriptive and analytical statistics were done, and the normality of the data was checked using Kolmogorov-Smirnov test. Since the normality for the distribution was not met, the nonparametric Kruskal-Wallis

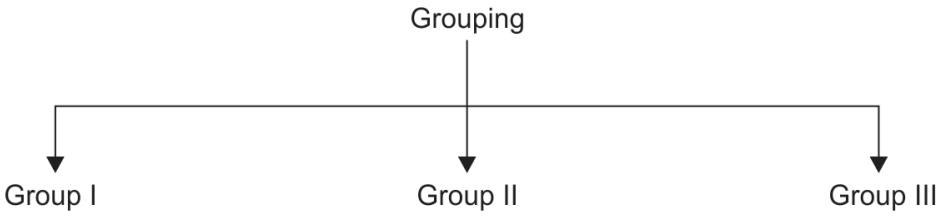

( $\mathrm{GIC}$ added to aqueous extract of triphala)

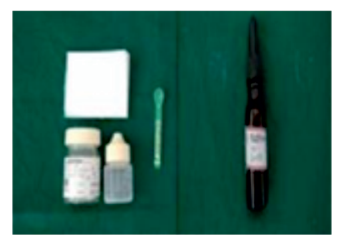

(GIC added to $50 \%$ ethanolic extract of propolis)

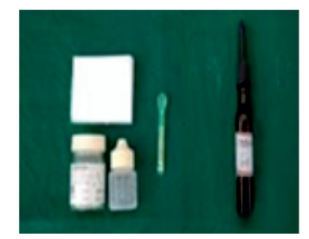

(Conventional GIC)

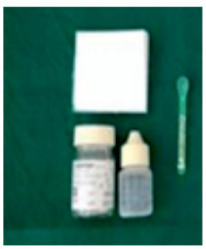

Fig. 1: Grouping 
test was used to check differences between the groups, and the pairwise comparison was done using Dunn-Bonferroni test. The level of significance was set at $<0.05$.

\section{Results}

\section{MIC Values}

For aqueous extract of triphala solution and for ethanolic extract of propolis, inhibition of S. mutans and Lactobacillus was at 0.15 $\mathrm{mg} / \mathrm{mL}$ and $0.1 \mathrm{mg} / \mathrm{mL}$, and $0.025 \mathrm{mg} / \mathrm{mL}$ and $0.022 \mathrm{mg} / \mathrm{mL}$, respectively. This present study proves superior antimicrobial activity of the triphala and propolis-modified GIC against S. mutans and Lactobacillus strain. The inhibition zones formed by groups I, II, and III are represented in Figure 4.

\section{Antibacterial Efficacy against S. mutans}

Antimicrobial efficacy on S. mutants between the three groups was tabulated and shown in Table 1. Group I when compared with group II showed effective antimicrobial efficacy without statistical significant difference between the groups ( $p$ value $>$ 0.05 ), whereas control group showed least antimicrobial efficacy with the difference being statistically significant ( $p$ value $<0.05$ ) (Table 2 and Fig. 5)

\section{Antibacterial Efficacy against Lactobacillus}

Antimicrobial efficacy on Lactobacillus between the three groups was tabulated and shown in Table 3. Group I when compared to group II showed highest mean diameter of inhibition zone against Lactobacillus, without statistically significant difference between the groups ( $p$ value $>0.05$ ), while the control group (group III)

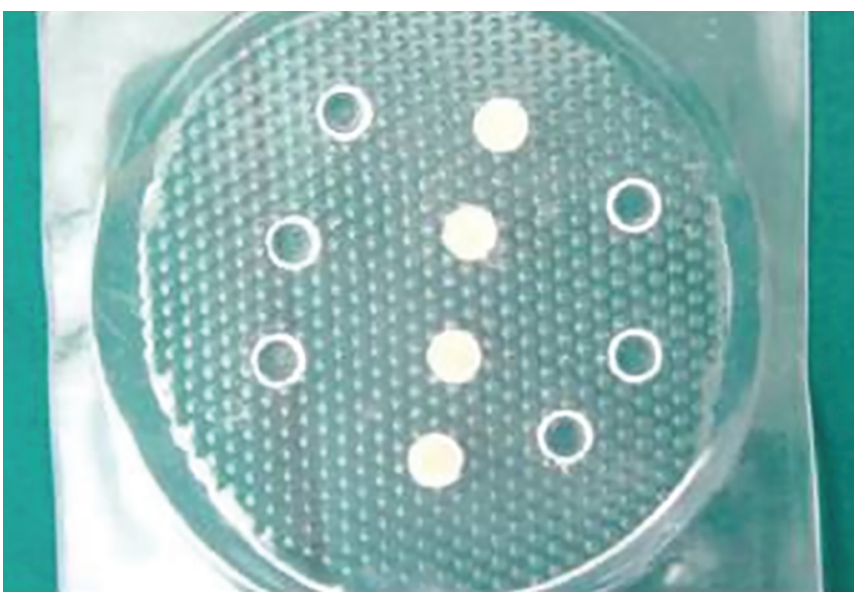

Fig. 2: Cylindrical moulds of $6 \times 2 \mathrm{~mm}$ failed to inhibit growth which showed least antimicrobial efficacy with the difference being statistically significant ( $p$ value $<0.05$ ). (Table 4 and Fig. 6)

\section{Discussion}

Dental caries is the most widespread dental disease in pediatric agegroup. Dental caries is initiated mainly by two groups of bacteria $S$. mutans and Lactobacilli. These bacteria cause carbohydrates mainly sucrose which are sticky in nature to form organic acid which in turn demineralizes and denatures the tooth substance leading to dental caries or cavity. Glucans, which facilitate the attachment of bacteria to the tooth surface, is synthesized by S. mutans with the help of glucosyltransferase (GTF). If dental caries is not managed in time, it leads to pain, infection, and in the later stages extraction of teeth which has a direct bearing on child's esthetics and functional occlusion.

Streptococcus mutans (ATCC 25175) has a profound effect on the incidence of dental decay in the human population; hence, it

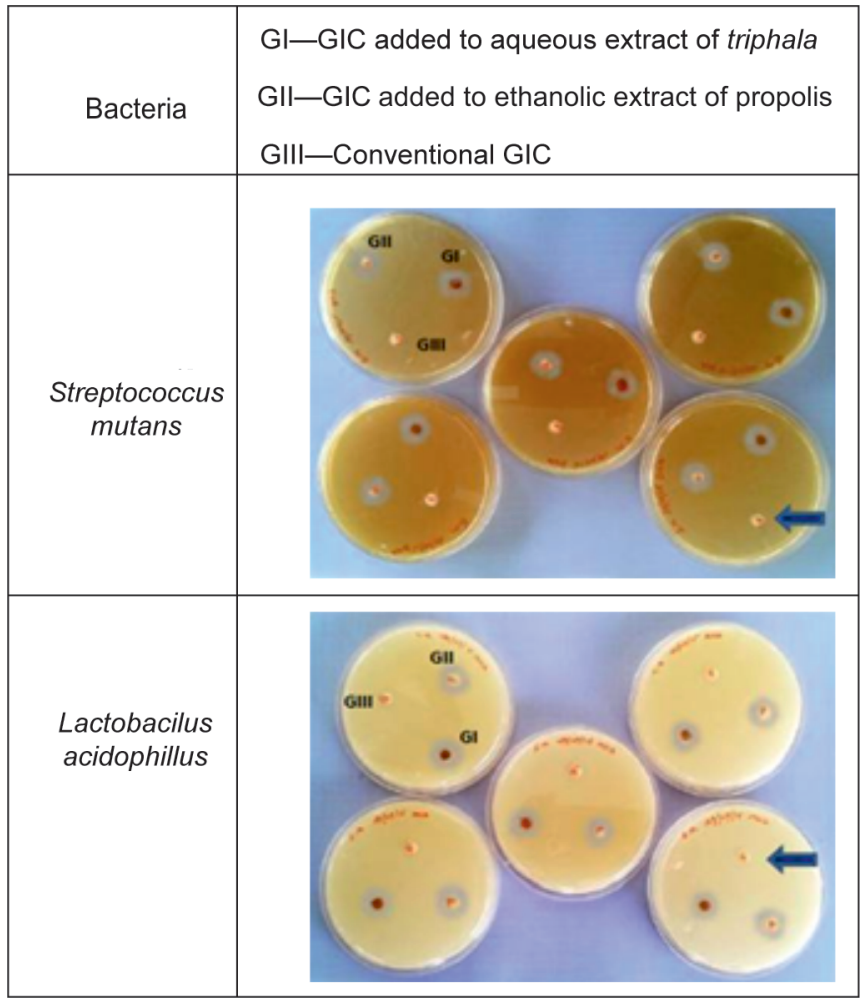

Fig. 4: Zone of inhibition against S. mutans and Lactobacillus for group I, group II and group III

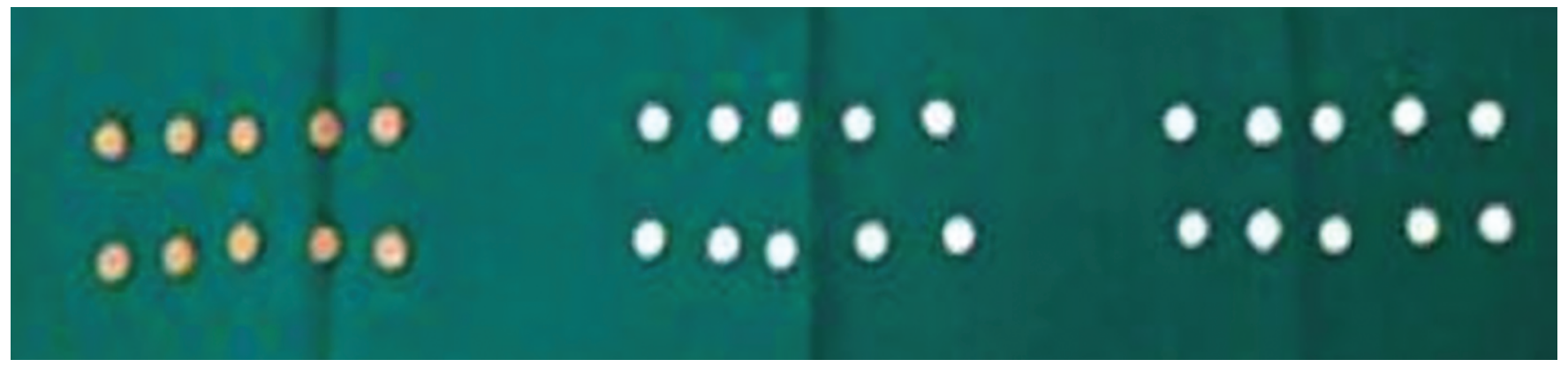

Fig. 3: 30 specimens 
Table 1: Comparison of antimicrobial efficacy on Streptococcus mutants between the three groups-group I (GIC with aqueous extract of triphala), group II (GIC with ethanolic extract of propolis) and control group (plain GIC)

\begin{tabular}{llllllll}
\hline Variables & $n$ & Mean & S.D. & Median & Min-Max & Test statistics & $p$ value \\
\hline Group I & 5 & 11.60 & 0.41 & 11.50 & $11.00-12.00$ & 9.795 & $0.007^{*}$ \\
Group II & 5 & 11.80 & 1.15 & 12.00 & $10.00-13.00$ & & \\
Control group & 5 & 05.50 & 0.50 & 05.50 & $05.00-06.00$ & \\
\hline
\end{tabular}

$p$ value derived from Kruskal-Wallis test; *Significant at $p<0.05$

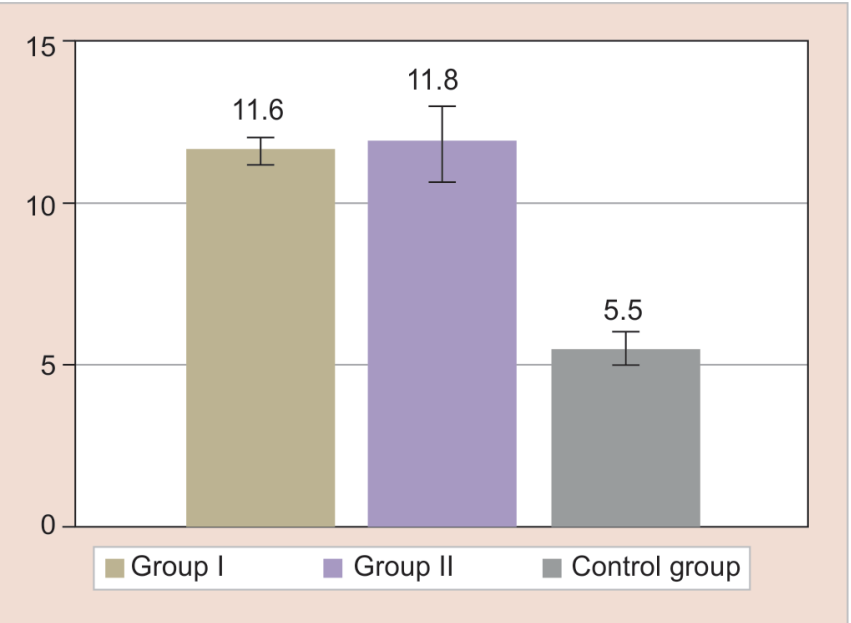

Fig. 5: Antimicrobial efficacy on Streptococcus mutants between the three groups - group I (GIC with aqueous extract of triphala), group II (GIC with ethanolic extract of propolis) and control group (Plain GIC). Note: The error bar represents the standard deviation of the mean

Table 2: Pairwise comparison of antimicrobial efficacy on Streptococcus mutants between the three groups - group I (GIC with aqueous extract of triphala), group II (GIC with ethanolic extract of propolis) and control group (plain $\mathrm{GIC}$ )

\begin{tabular}{lccl}
\hline Variables & $N$ & Test statistics & p value \\
\hline Group I v/s group II & 5 & -1.400 & 1.000 \\
Group I v/s control group & 5 & 2.426 & $0.046^{*}$ \\
Group II v/s control group & 5 & 2.925 & $0.010^{*}$ \\
\hline
\end{tabular}

Pairwise comparison done by Dunn-Bonferroni test; *Significant at $p<0.05$

was selected for the study. Lactobacillus are highly acidogenic from carbohydrates and are acid tolerant, and they are often cultured from established carious lesions. ${ }^{17}$

\section{Conventional GIC}

Among the widespread restorative materials used in dentistry, the conventional GICs were selected in this study due to their major advantages of adhesion to tooth structure, fluoride uptakes, and release which can inhibit caries, furthermore the variety of the clinical application of GICs. ${ }^{16}$

Nakajo et al. concluded S. mutans on the surface of GIC fillings was less than on composite resin fillings. ${ }^{18}$ Hoszek et al. said that conventional GICs have low bactericide potential which can act against microorganisms to the certain extent. Therefore, the ability of GICs in complete elimination of the plaque proliferation, caries development, and periodontal disease in few patients is still questionable. ${ }^{19}$ Also, following insertion of GICs in to the cavity, it has been proved that approximate release of fluoride is around $10 \mathrm{ppm}$ which is still considered low for attaining the desired

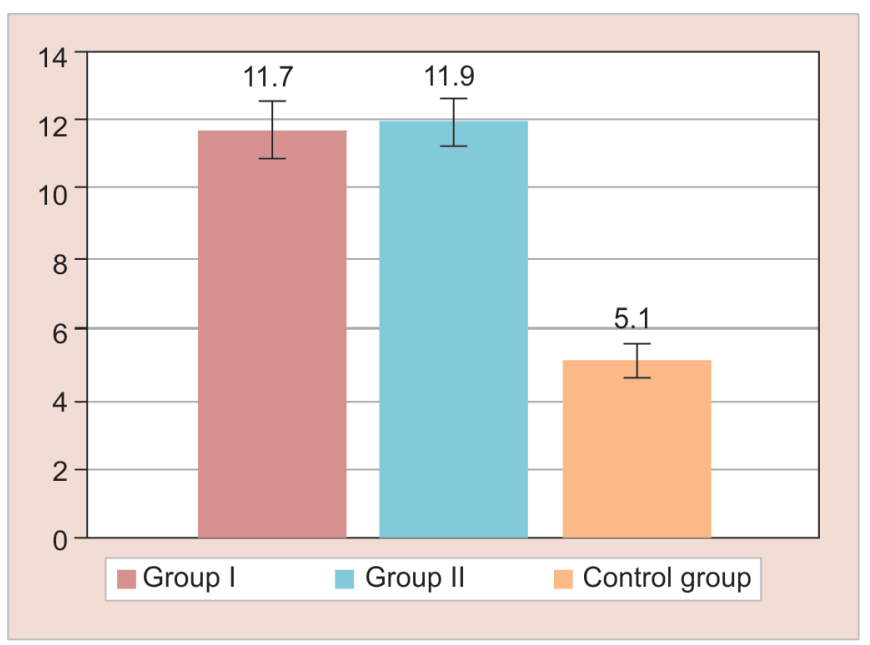

Fig. 6: Antimicrobial efficacy on Lactobacillus between the three groups-group I (GIC with aqueous extract of triphala), group II (GIC with ethanolic extract of propolis) and control group (Plain GIC). Note: The error bar represents the standard deviation of the mean

antibacterial effects. ${ }^{16,20}$ Hence, GIC was not able to hold its acidity and fluoride ion after a particular point of time. Yap et al. ${ }^{21}$ stated that even with the presence of fluoride content in GIC, the expected efficient antimicrobial property is yet difficult to achieve; hence, the motto of this present study was to improve the antimicrobial characteristics of GIC; therefore, the modification using triphala and propolis was done.

\section{Antibacterial Efficacy of GIC Containing Aqueous Extract of Triphala}

In the present study, group I had showed the more inhibition of $12.5 \mathrm{~mm}$, whereas conventional GIC shows inhibition of $5 \mathrm{~mm}$. This confirms the earlier studies that the inhibition of GIC against caries formation is solely due to fluoride release and/or acidity, ${ }^{22}$ and the inhibition of microorganisms by conventional GICs in cavities is not reliable. ${ }^{23}$ The antimicrobial efficacy of GIC with triphala may be due to the following reasons, which is proven by numerous literatures:

In the main ingredient of Triphala, Terminalia chebula acts as a anticaries agent, ${ }^{24,25}$ as it prevents sucrose-induced adherence, thereby eliminating the virulence of cavity-inducing organisms. According to Biradar et al., triphala can retard the growth of bacteria ${ }^{26}$ and also Jagtap and Karkera reported that extracts of main ingredient in triphala, i.e., Terminalia chebula, prevents the growth and adherence of S. mutans. ${ }^{27}$

Also, another ingredient Terminalia bellerica (in Triphala), which contains tannic acid, can be adsorbed to the surface of the bacterial cells, resulting in protein denaturation and bacterial cell death. ${ }^{28} \mathrm{Kau}$ et al. reported that tannic acid is bacteriostatic or bactericidal to few pathogens. ${ }^{29}$ It may be a reason for the present study in the enhancement of antimicrobial activity. The 
Antimicrobial Efficacy of Triphala and Propolis-modified Glass Ionomer Cement

Table 3: Comparison of antimicrobial efficacy on Lactobacillus between the three groups-group I (GIC with aqueous extract of triphala), group II (GIC with ethanolic extract of propolis) and control group (plain GIC)

\begin{tabular}{llllllll}
\hline Variables & $n$ & Mean & S.D. & Median & Min-Max & Test statistics & $p$ value \\
\hline Group I & 5 & 11.70 & 0.83 & 11.50 & $11.00-13.00$ & 9.639 & $0.008^{*}$ \\
Group II & 5 & 11.90 & 0.65 & 12.00 & $11.00-12.50$ & & \\
Control group & 5 & 05.10 & 0.74 & 05.00 & $04.00-06.00$ & \\
\hline
\end{tabular}

$p$ value derived from Kruskal-Wallis test; ${ }^{*}$ Significant at $p<0.05$

Table 4: Pairwise comparison of antimicrobial efficacy on Lactobacillus between the three groups-group I (GIC with aqueous extract of triphala), group II (GIC with ethanolic extract of propolis) and control group (plain GIC)

\begin{tabular}{lccl}
\hline Variables & $n$ & Test statistics & $p$ value \\
\hline Group I v/s group II & 5 & -0.356 & 1.000 \\
Group I v/s control group & 5 & 2.493 & $0.038^{*}$ \\
Group II v/s control group & 5 & 2.849 & $0.013^{*}$ \\
\hline
\end{tabular}

Pairwise comparison done by Dunn-Bonferroni test; *Significant at $p<0.05$

study conducted by Srinagesh et al. suggested that the anti-oral streptococci efficacy of triphala and chlorhexidine are quite similar and comparable. ${ }^{7}$ Also, similar results were obtained by Jagadish et al. ${ }^{30}$ and Prajapathi and Raol. ${ }^{31}$ Another study done by Prabhakar et al. proved the statistical significance, with triphala being highly antibacterial when compared with chlorhexidine. ${ }^{32}$ The antibacterial efficacy of type IX GIC had the least antimicrobial efficacy which was in accordance with our results. ${ }^{33}$ This can be reason for the triphala-modified GIC to show superior antimicrobial activity.

\section{Antibacterial Efficacy of GIC Containing Ethanolic Extract of Propolis}

In the present study, group II had showed the superior inhibition of $13.0 \mathrm{~mm}$ when compared to the other two groups. The antimicrobial activity of GIC added propolis is mainly due to two mechanisms of action associated with propolis, (1) anti-microbial activity and (2) inhibits glucosyl transferase activity. ${ }^{34}$

The superior microbicidal compounds present in EEP is galangin and caffeic acids, which play a role in inhibition of bacterial growth and proliferation. ${ }^{35,36}$ Next is the flavonoids that causes alteration in permeability of microorganisms. A previous literature has revealed that the components present in the propolis have an inability to bind to DNA, resulting in the inhibition of bacterial RNApolymerase. Hence, these components, galangin, caffeic acids, and flavonoid, are considered to be bacterial enzymes inhibitors ${ }^{35,37-40}$ which was a major reason in causing antimicrobial efficacy when mixed with GIC.

Viable bacteria were found to be less in the GIC containing $50 \%$ EEP when compared to 25\% EEP. Hence, 50\% EEP was used in the present study. ${ }^{41}$ Also his study proved that distinct antibacterial activity of propolis containing GIC against S. mutans which is in accordance with our results. Also, another study done by Ophori et al. concluded that EEP is highly antibacterial; hence, it is suggested to treat dental caries. ${ }^{42} \mathrm{~A}$ study done by Erdem et al. proved that addition of Ethanolic extract of propolis to GIC will increase the antimicrobial efficacy without altering its properties. ${ }^{42}$ Hence, the promising results were obtained when ethanolic extract of propolis were added with GIC. ${ }^{43}$

\section{Clinical Significance}

Atraumatic restorative treatment (ART) has been developed for treatment of caries in parts of world with limited access to dental treatment facilities, where demineralized soft carious lesion are excavated and it is restored with suitable adhesive restorative materials. As dental hand instruments solely cannot help in removal of entire carious lesion, there may be chances of remnant cariogenic bacteria which can survive in depth underneath the restorations. Consequently, when the restoration (GIC) is not capable to arrest the carious progression, the restoration will result in failure. As researchers proved that few ART restorations fail because of secondary caries development over a period of 6 years, there lies a need for improvement in filling materials which can overcome the problem resulting in success rate of ART. Hence, the GIC containing propolis and triphala will be beneficial to prevent secondary caries formation and would be used as a promising material for restoration. Further extensive research is required in regard to physical, mechanical properties and bonding effects of GIC which can promote a novel natural bioactive restorative material.

\section{Conclusion}

The results of this present study proved that modified GIC with triphala and propolis had a maximum zone of inhibition proving its higher antimicrobial efficacy against S. mutans and Lactobacillus when compared to conventional GIC. Therefore, propolis and triphala added GIC can be a better replacement for restoring of the dental cavities. Future investigations are required to know about its physical and mechanical properties.

\section{References}

1. Carvalho JC, Ekstrand KR, Thylstrup A. Dental plaque and caries on occlusal surfaces of first permanent molar in relation to stage of eruption. J Dental Res 1989;68(5):773-779. DOI: 10.1177/00220345890680050401.

2. Powell LV. Caries prediction: a review of the literature. Commun Dent Oral Epidemiol 1998;26(6):361-371. DOI: 10.1111/j.1600-0528.1998. tb01974.x.

3. Tobias RS. Antibacterial properties of dental restorative materials. Int Endod J 1998;21(2):155-160. DOI: 10.1111/j.1365-2591.1988.tb00969.x.

4. Wiegand A, Buchalla W, Attin T. Review on fluoride-releasing restorative materials- fluoride release and uptake characteristics, antibacterial activity and influence on caries formation. Dent Mater 2007;23(3):343-362. DOI: 10.1016/j.dental.2006.01.022.

5. Nadkarni AK. Dr. K. M. Nadkarni's Indian Materia Medica with ayurvedic, unani-tibbi, siddha, allopathic, homeopathic, naturopathic and home remedies, appendices and indexes. 3rd ed., Bombay: Popular Prakashan; 1976. pp. 120-128.

6. Juss SS. Triphala - the wonder drug. Ind Med Gaz 1997;131:194-196.

7. Srinagesh J, Krishnappa P, Somanna SN. Antibacterial efficacy of triphala against oral streptococci: an in vivo study. Indian J Dent Res 2012;23(5):696. DOI: 10.4103/0970-9290.107423. 
8. Kumazawa S, Hamasaka T, Nakayama T. Antioxidant activity of propolis of various geographic origins. Food Chem 2004;84(3):329339. DOI: 10.1016/S0308-8146(03)00216-4.

9. Kujumgiev A, Tsvetkova I, Serkedjieva Y, et al. Antibacterial, antifungal and antiviral activity of propolis of different geographic origin. J Ethnopharmacol 1999;64(3):235-240. DOI: 10.1016/s03788741(98)00131-7.

10. Russo A, Cardile V, Sanchez F, et al. Chilean propolis: antioxidant activity and antiproliferative action in human tumor cell lines. Life Sci 2004;76(5):545-558. DOI: 10.1016/j.Ifs.2004.07.019.

11. Yang HY, Ho WL, Chang CM, et al. Antibacterial activity of propolis ethanol extract against Streptococcus mutans as influenced by concentration, temperature, $\mathrm{pH}$ and cell age. J Food Drug Anal 2007;15(1):75-81.

12. Uzel A, Sorkun K, Oncag O, et al. Chemical compositions and antimicrobial activities of four different anatonian propolis samples. Microbiol Res 2005;160(2):189-195. DOI: 10.1016/j.micres.2005.01.002.

13. de Carvalho Duailibe SA, Gonçalves AG, Mendes Ahid FJ. Effect of a propolis extract on Streptococcus mutans counts in vivo. J Appl Oral Sci 2007;15(5):420-423. DOI: 10.1590/S1678-77572007000500009.

14. Jacob SW, Herschler R. Biological actions of dimethyl sulfoxide. Ann N Y Acad Sci 1975;243:1-508.

15. Biological actions and medical applications of dimethyl sulfoxide. Ann NY Acad Sci 1983;411(1 Biological Ac):1-404. DOI: 10.1111/j.17496632.1983.tb47277.x.

16. Takahashi $Y$, Imazato S, Kaneshiro AV, et al. Antibacterial effects and physical properties of glass-ionomer cements containing chlorhexidine for the ART approach. Dent Mater 2006;22(7):647-652. DOI: 10.1016/j.dental.2005.08.003.

17. Tanzer JM, Livingston J, Thompson AM. The microbiology of primary dental caries in humans. J Dent Educ 2001;65(10):1028-1037. DOI: 10.1002/j.0022-0337.2001.65.10.tb03446.x.

18. Nakajo K, Imazato S, Takahashi Y, et al. Fluoride released from glassionomer cement is responsible to inhibit the acid production of caries-related oral streptococci. Dent Mater 2009;25(6):703-708. DOI: 10.1016/j.dental.2008.10.014.

19. Hoszek A, Ericson D. In Vitro fluoride release and the antibacterial effect of glass ionomers containing chlorhexidine gluconate. Oper Dent 2008;33(6):696-701. DOI: 10.2341/08-20.

20. Mazzaoui SA, Burrow MF, Tyas MJ. Fluoride release from glass ionomer cements and resin composites coated with dentin adhesive. Dent Mater 2000;16(3):166-171. DOI: 10.1016/s0109-5641(00) 00003-8.

21. Yap AU, Khor E, Foo SH. Fluoride release and antibacterial properties of new-generation tooth-colored restoratives. Oper Dent 1999;24(5):297305.

22. Marthaler TM. Changes in dental caries 1953-2003. Caries Res 2004;38(3):173-181. DOI: 10.1159/000077752.

23. Van Amerongen WE. Dental caries under glass ionomer restorations. J Public Health Dent 1996;56(3 Spec No):150-154. DOI: 10.1111/j.17527325.1996.tb02426.x.

24. Date BB, Kulkarni PH. Assessment of Rasadanti in various oral disorders. Ayurveda Res Pap 1995;2:175-197.

25. Bhavikatti SK, Dhamija R, Prabhuji MLV. Triphala: envisioning its role in dentistry. Int Res J Pharm 2015;6(6):309-313. DOI: 10.7897/22308407.06667.

26. Biradar YS, Jagatap S, Khandelwal KR, et al. Exploring of antimicrobial activity of triphala mashi-an ayurvedic formulation. Evid Based
Complement Alternat Med 2008;5(1):107-113. DOI: 10.1093/ecam/ nem002.

27. Jagtap AG, Karkera SG. Potential of the aqueous extract of Terminalia chebula as an anticaries agent. J Ethnopharmacol 1999;68(3):299-306. DOI: 10.1016/s0378-8741(99)00058-6.

28. Bonesvoll P, Lokker P, Rolla G, et al. Retention of chlorhexidine in the human oral cavity after mouthtrinses. Arch Oral Biol 1974;19(3):209212. DOI: 10.1016/0003-9969(74)90263-5.

29. Kau PC. New Chinese Medicine Handbooks 1 Wu B, ed., China: Shing Wen Fang Publishing; 1980. pp. 288-291.

30. Jagadish L, Anand Kumar VK, Kaviyarasan V. Effect of triphala on dental bio-film. Indian J Sci Technol 2009;2(1):30-33. DOI: 10.17485/ ijst/2009/v2i1.13.

31. Prajapati RA, Raol BV. The study on the efficacy of some herbal extracts for the control of dental caries pathogen-Streptococcus mutans. Int J Pharm Sci Health Care 2014;1:49-80.

32. Prabhakar J, Balagopal S, Priya MS, et al. Evaluation of antimicrobial efficacy of triphala (an Indian ayurvedic herbal formulation) and $0.2 \%$ chlorhexidine against Streptococcus mutans biofilm formed on tooth substrate: an in vitro study. Indian J Dent Res 2014;25(4):475-479. DOI: 10.4103/0970-9290.142539.

33. Mathew SM, Thomas AM, Koshy G, et al. Evaluation of the microleakage of chlorhexidine-modified glass ionomer cement: an in vivo study. Int J Clin Pediatr Dent 2013;6(1):7-11. DOI: 10.5005/ jp-journals-10005-1177.

34. Koo H, Smith VAM, Bowen WH, et al. Effects of apis mellifera propolis on the activities of streptococcal glucosyltransferases in solution and adsorbed onto saliva-coated hydroxyapatite. Caries Res 2000;34(5):418-442. DOI: 10.1159/000016617.

35. Mirzoeva OK, Grishanin RN, Colder PC. Antimicrobial action of propolis and some of its components: the effect on growth, membrane potential and motility of bacteria. Microbiol Res 1997;152(3):239-246. DOI: 10.1016/S0944-5013(97)80034-1.

36. Kosalec I, Bakmaz M, Pepeljnjak S. Analysis of propolis from the continental and adriatic regions of Croatia. Acta Pharm 2003;53(4):275-285.

37. Havsteen B. Flavonoids, a class of natural products of high pharmacological potency. Biochem Pharmacol 1983;32(7):1141-1148. DOI: 10.1016/0006-2952(83)90262-9.

38. Trusheva B, Trunkova D, Bankova V. Different extraction methods of biologically active components from propolis: a preliminary study. Chem Cent J 2007;1(1):13-17. DOI: 10.1186/1752-153X-1-13.

39. Silva BB, Rosalen PL, Cury JA, et al. Chemical composition and botanical origin of red propolis, a new type of Brazilian propolis. Evidence-Based compl Alt Med 2007;5(3):313-316. DOI: 10.1093/ ecam/nem059.

40. Kartala M, Yıldızb S, Kayaa S, et al. Antimicrobial activity of propolis samples from two different regions of Anatolia. J Ethnopharmacol 2003;86:(1):69-73. DOI: 10.1016/S0378-8741(03)00042-4.

41. Topcuoglu N, Ozan F, Ozyurt M, et al. In vitro antibacterial effects of glassionomer cement containing ethanolic extract of propolis on Streptococcus mutans. European J Dent 2012;6:428-433.

42. Ophori EA, Eriagbonye BN, Ugbodaga P. Antimicrobial activity of propolis against Streptococcus mutans. Afr J Biotechnol 2010;9(31):4966-4969.

43. Hatunoglu E, Ozturk F, Bilenler T, et al. Antibacterial and mechanical properties of propolis added to glass ionomer cement. Angle Orthodontist 2014;84(2):368-373. DOI: 10.2319/020413-101.1. 